\title{
Samba, futebol e democracia? A cobertura do movimento "Diretas Já" pela imprensa francesa \\ Isabel Travancas
}

\section{RESUMO}

O objetivo deste artigo é analisar e discutir a cobertura da imprensa francesa do movimento pelas eleiçōes diretas - "Diretas Já"- ocorrido no pais em 1984. A partir da seleção de matérias dos jornais Libération e Le Monde, avalia-se em que medida os textos jornalisticos apresentam o Brasil através de estereotipos e clichês. Para tal é discutida a noção de exótico e de etnocentrismo à luz de alguns pensadores das ciências sociais, particularmente da antropologia, da sociologia e da história.

\section{ABSTRACT}

The purpose of this paper is andyse and discuss the fremch press coverage of the diret election movenent happened in Brazil in 1984, called "Diretas Já". In Liberation and Le Monde newspapers selected articles, the' use of stereotype and diche to present Brazil is measured. The concept of exotic and ethnocentrism is discussed in a view of some thinkers of social science, specially anthropology, sociology and history.

Jornalista, mestre em Antropologia Social pelo Museu Nacional-UFRJ, doutora em Literatura Comparada-UERJ. Professora do Departamento de Antropologia Cultural do IFCS-UFRJ e da Faculdade de Comunicação Social da Estácio de Sá. Aurora de O Mundo dos Jornalistas, SP. Summus Editorial, 1993. 


\section{Introdução}

O movimento político, ou melhor, a campanha pelas eleições diretas ocorrida no Brasil em 1984 foi um marco e certamente um divisor de águas no cenário político nacional. Havia muito tempo que grande parte da população brasileira não se manifestava politicamente com tanta intensidade nas ruas. Ainda que a emenda Dante de Oliveira, votada no dia 25 de abril de 1984 no Congresso Nacional, não tenha sido aprovada, o movimento alcançou uma força e dimensão inimagináveis em seu início, principalmente se pensarmos que o Brasil ainda estava vivendo sob o jugo dos militares, tendo o general João Figueiredo como presidente.

O que busco com este trabalho é avaliar como é descrito pela imprensa estrangeira um movimento político brasileiro de grande dimensões. Ou seja, entender quais as grandes questões destacadas e qual a visão dos jornais do país e de sua política, assim como perceber se há uma representação a priori do Brasil. E se há, em que medida ela é reforçada ou desconstruída na cobertura das "Diretas Já".

Escolhi avaliar a cobertura jornalística francesa por perceber que há uma estreita relação entre os dois países e um grande interesse da França pelo Brasil, sua música, sua arte, sua política e seu futebol, o que se expressa nas páginas de seus principais diários. É grande a co84 bertura do Brasil na editoria Étranger dos dois jornais em comparação com outros países da América Latina, por exemplo.

E para tal decidi analisar os seguintes jornais: Le Monde e Libération. Os dois jornais nutriram seus leitores com muitas informações sobre o Brasil e o movimento ao longo do mês, chegando as "Diretas Já" a serem em ambos matéria de capa além de tema de editoriais

Gostaria de poder ainda avaliar como algumas categorias associadas à imagem do Brasil no exterior, como o carnaval, a festa e o futebol estão presentes nas matérias jornalísticas destes dois cotidianos e, em que medida as reportagens lançam mão de estereótipos e clichês para falar do Brasil.

Creio que, ao lado desses fatores, esta reflexão pode ser um contraponto interessante para a própria cobertura dos jornais nacionais e um elemento valioso de análise da identidade nacional elaborada pela imprensa estrangeira.

\section{Os Jornalistas e os Jornais}

O jornalismo, como ocupação própria da sociedade moderna, exerce uma grande atração para muitos indivíduos, seja pelo seu papel 
social, seja por ele ser visto como instrumento de obtenção de poder e sucesso. E o envolvimento desses indivíduos com a profissão é imenso. Eles vivem o que denominei "adesão" (Travancas: 1993), ou seja. uma experiência na qual a profissão passa a ocupar um enorme espaço em suas vidas tornando-se o elemento fundamental para a construção da identidade dessas pessoas. E a escolha desse papel como o principal em suas vidas vai gerar um "estilo de vida" e uma "visão de mundo" particulares, de acordo com G. Velho (1987:105). A percepção da sociedade e sua compreensão, assim como a maneira de viver. vão estar profundamente influenciadas pela profissão, não apenas em termos políticos, mas no aspecto existencial e simbólico.

Saliento tudo isto porque creio que é possível fazer uma leitura da cobertura destes jornais como resultado dessa visão de mundo. o que explica as semelhanças. Não são determinações rígidas ou externas aos indivíduos, mas uma maneira particular de ver o mundo. É como se o mundo pudesse ser lido e compreendido dentro das páginas de um jornal, ou a partir delas, o que me lembra o depoimento de um jornalista "imbuído" de sua profissão que não conseguia ouvir uma história sem pensar se ela daria uma boa matéria jornalística...

Atualmente, um grande jornal é uma empresa que produz milhares de exemplares, com estrutura organizacional bem planejada e administrada. e com muitos funcionários em diferentes áreas de atuação.

O "coração" de um jomal é a redação. É nela que são produzidas as notícias. mercadoria "vendida" pelo jomal e sua razão de ser. A redação se divide em editorias que são setores do jornal. Um grande jornal tem cerca de dez editorias diferentes que agrupam repórteres, redatores, diagramadores, editores, subeditores e chefes de reportagem.

Esta divisão em editorias aponta para una topografia do conhecimento, onde os diferentes saberes são distribuídos em áreas estanques e distintas fïsicamente. Separação essa que busca ser uma expressão da realidade, como se a vida pudesse ser e fosse compartimentada em seções. Da mesma forma, é interessante perceber as fronteiras entre as editorias e o que é considerado como pertencente a uma e não a outra. A própria campanha das "Diretas Já" poderia também estar colocada na seção de política, ao invés da "Étranger". por exemplo. Mas isso não ocorre porque, antes de ser uma fato político, ele é exterior à França.

Assim. no caso da cobertura jomalística do Brasil, estamos lidando com a editoria intemacional ou "étranger" como é chamada na França. Vale um comentário sobre a escolha do nome da editoria. A palavia étranger cuja tradução é estrangeiro também pode ser estranho. Ou seja, ela tratará do que é estrangeiro ao francês e que pode ser também estranho, o que já diz um pouco do que o leitor espera 
desta seção que poderia ser intitulada internacional, mundo ou exterior. Mas a idéia presente nos jornais é o que não é a França, o que está fora dela.

Nesse sentido, destaca-se a construção da realidade que é feita pelo "mundo do jornal". Ou seja, para um jornalista a vida será pautada, dividida e compreendida a partir destas divisões em editorias e assuntos, o que é fruto de uma necessidade do homem de classificar, e que já foi apontada por inúmeros antropólogos: classificar para compreender e também. para reorganizar. É inevitável lembrar da obra de E. Durkheim e M. Mauss (1981:403) sobre o sistema de classificação dos homens. Para os dois autores, essa é uma necessidade básica do homem. É a maneira de transformar o real em dimensões inteligíveis:

"Toda classificação implica uma ordem hierárquica da qual nem o mundo sensível nem nossa consciência nos ofereceu um modelo. Deve-se pois, perguntar onde fomos procurá-lo."

Assim, percebe-se que tanto a natureza, em um primeiro momento, como mais tarde a própria sociedade não são "coisas" dadas $a$ priori, são construções do pensamento. E o jornal é um instrumento de comunicação e também de representação. A representação que os jornais fazem da realidade é uma construção dessa mesma realidade. E um dos pilares desta construção é a criação e a organização da vida em "editorias" e "seções", e consequientemente em hierarquias.

Aqui vale um comentário para a relação estreita entre a imprensa, os jornalistas e os eventos políticos. Não é por acaso que os jornalistas franceses se definem como intelectuais, termo que aponta para o papel de agente transformador do jornalista e da imprensa, pois para a França, assim como para a grande maioria das sociedades européias, a categoria intelectual enquanto entidade autônoma e carregada de capital simbólico e político - não apenas como atividade que se coloca em oposição à atividade manual-, se constitui enquanto tal com o affaire Dreyfus. É o historiador Christophe Charle (1990) quem salienta este fato em seu livro sobre o nascimento dos intelectuais na França. Para ele, esta categoria nasceu com a polêmica e o julgamento do capitão Dreyfus em 1890, cujo ápice foi a publicação no jornal L'Aurore do texto "J'accuse" de Emile Zola, de apoio ao capitão e contra a sua condenação. O conceito designava uma camada política e culturalmente progressista que desafiava o Estado. Jornalistas, escritores, artistas e políticos se manifestaram publicamente e influenciaram o rumo dos acontecimentos, e a imprensa teve um papel fundamental como demonstra Jean Yves Mollier em seu artigo "La presse et l'édition dans la bataille dreyfusienne".(1995:80)

Ao buscar captar a ótica dos jornalistas franceses em relação a um 
movimento político brasileiro, faz-se necessário destacar alguns pontos. Como se trata de imprensa distinta do país onde ocorre a campanha, não é possível se falar em influências ou mesmo em poder por parte dos jornais, na medida em que a população brasileira, em sua grande maioria, não tomou conhecimento do que foi noticiado na França. Os correspondentes aqui no Brasil e seus editores na França produziam matérias para seus leitores franceses na França ou no exterior. No entanto, uma primeira página no Le Monde tem grande repercussão para além do número exclusivo de seus leitores. Afinal, uma notícia tem um peso maior ou menor em função do lugar do jornal dentro do campo jornalístico internacional. Le Monde é, sem dúvida alguma, uma fonte importante para outros jornais estrangeiros.

Ainda sobre o papel dos correspondentes dentro do jornal, há vários aspectos a serem destacados. Eles ocupam um lugar importante na redação. Estão no topo da hierarquia e para inúmeros jornalistas ser correspondente é uma das funções mais cobiçadas, seja pelo destaque que suas matérias recebem, pelas possibilidades de morar no exterior e viajar, além dos salários mais elevados. Ou seja, ser correspondente internacional significa ter ascendido profissionalmente e possuir status e notoriedade no meio.

Por outro lado, os correspondentes são intermediários entre o "o mundo exterior" e o leitor. Eles devem conhecer o país que noticiam, mas precisam ter em mente o público do "seu" jornal. Não é à toa que o historiador norte-americano R. Darnton (1990:83), escrevendo sobre a sua experiência como repórter do The New York Times, comenta que o jornal desconfia tanto que seus repórteres tornem-se favoráveis ao país onde moram, que os transferem de três em três anos. O jornal quer assim evitar que os seus jornalistas se "integrem demais" ao país, diminuindo o seu distanciamento e, principalmente, que percam de vista o leitor para quem escrevem e suas respectivas visôes de mundo.

\section{Le Monde}

Dentro do campo jornalístico francês optei por Le Monde e Libération por serem dois jornais importantes na França e por terem estilo, formato e conteúdos bastante distintos. Le Monde é o jornal francês de maior prestígio internacional. Variedade de informações e articulistas respeitados, além de uma postura política "independente" fazem a essência de um jornal de estilo sóbrio, até bem pouco tempo sem fotografias, cor e com pouca publicidade. Fundado em 1944 por Hubert Beuve-Méry, Le Monde veio ocupar um vazio na imprensa de pós- 
guerra e se tornou o representante da família democrata cristã. Sua estrutura interna é bem diferente da maioria das empresas jornalísticas, com seus redatores possuindo $40 \%$ do capital. Seu formato difere dos outros veículos da imprensa francesa pelo parco uso de fotos e por oferecer textos extensos e analíticos. Ele tem ainda uma particularidade: circula à tarde. Le Monde possui um lugar estável e de destaque dentro da.imprensa, apesar das diversas crises financeiras por que passou, e desempenha um papel importante junto à intelectualidade e à classe política. Pierre Bourdieu (1997:60), em seu ensaio sobre o campo jornalístico na França, comenta o papel do jornal:

"Pode-se dizer que, no universo do jornalismo francês, Le Monde ditava a lei. Havia já um campo, com a oposição, estabelecida por todos os historiadores do jornalismo, entre os jornais que dão news, notícias, variedades, e os jornais que dão views, pontos de vista, análises, etc.(...) Le Monde estava bem situado sob os dois aspectos: era suficientemente grande por sua tiragem para ser um poder do ponto de vista dos anunciantes e suficientemente dotado de capital simbólico para ser uma autoridade. Acumulava os dois fatores do poder desse campo."

Le Monde reinava e ainda reina, e possui o melhor dos dois mundos. Como dizem os franceses, uma matéria no Monde sobre alguma questão política pode influenciar os dirigentes do país, da mesma forma que, segundo dados de 1995 do Instituto de Pesquisas e Estatísticas EUROPQN, uma resenha no jornal é 50\% mais eficaz sobre as vendas do que se publicada em outro órgão de imprensa. Isso porque o jornal conseguiu estabelecer uma imagem de respeito e credibilidade junto à opinião pública.

\section{Libération}

Bem mais recente - nascido em 1973 - o jornal Libération se apresentou ao leitor, na ocasião, como um jornal para o povo, tendo o intelectual Jean Paul Sartre como um de seus diretores. O jornal foi criado a partir de um fundo de doações, sem anúncios e com umạ posição política declaradamente de esquerda. Dirigido por um grupo de maoístas "herdeiros" do espírito revolucionário de maio de 68, conseguiu conquistar o público. Ao longo desses anos, enfrentou desafios financeiros e editoriais, passou a incluir a publicidade em suas páginas e manteve uma atitude política de esquerda. Tablóide e matutino, com um projeto editorial ousado, tanto em termos políticos, como visuais e estilísticos, Libération já sofreu diversas reformas. Desde quando foi criado certamente o Libé, como é chamado por seus leitores, se afastou da idéia que professava no início (Samuelson, 1979:149): "Libération sera l'oeil du peuple sur l'organization de la societé civile". 
Ele é hoje uma empresa e como tal visa o lucro, mas não perdeu sua jovialidade nem suas páginas com caricaturas e desenhos, utilizando uma linguagem que faz jogos de palavras e brinca com seu sentido em títulos e manchetes de forma pouco usual na grande imprensa.

\section{Abril de 1984 na França}

Enquanto no Brasil crescia em tamanho e intensidade o movimento pelas "Diretas Já" e sua cobertura pela imprensa era cada vez mais ampla, nos jornais franceses também aumentava a presença brasileira em suas páginas. Durante o mês de abril de 1984, o Brasil foi tema de 11 matérias no Le Monde e 17 no Libération. Vale ressaltar que. para esta análise, serão levadas em conta exclusivamente as reportagens sobre a campanha pelas eleições diretas. Entrelanto, destaco que Le Monde teve quatro matérias cujos assuntos foram: "Os índios em pé de guerra... em Brasilia", notícia que trata do protesto dos índios pedindo a demissão do presidente da FUNAI; uma matéria-dossiê sobre a fome na América Latina', que fala do Brasil e tem imagens do fotógrafo brasileiro Sebastião Salgado: uma nota grande na rubrique música - jazz sobre o compositor brasileiro João Bosco. que estava em Paris naquela ocasião fazendo um show, e uma grande reportagem intitulada "Faz vinte anos o golpe que pôs fim à democracia brasileira - O longo saborear dos generais", assinada pelo correspondente do jornal no Rio, Charles Vanhecke, e que traz um balanço histórico dos 20 anos do golpe militar no Brasil.

No Libération 11 matérias tiveram as "Diretas Já" como tema e seis trataram de outros temas. Uma aborda o FMI e a divida externa dos países da América Latina; outra noticia os mortos na guerra da castanha de caju. "La samba triste des pavs d'Amerique Latine" é o título de uma reportagem de meia página sobre a crise econômica dos países da América Latina. As inundações no Nordeste são o tema da notícia seguinte, narrando a tragédia dos nordestinos, que. depois de sofrerem durante anos com a seca, agora sofrem com as inundações que deixaram milhares de pessoas desabrigadas. A última notícia sobre o Brasil aborda o show do músico João Bosco em Paris e tem a sugestiva manchete: "Le présidente Bosco" associando o nome do compositor ao movimento político.

Entretanto, pode-se notar com a leitura das reportagens o quanto a campanha em si, como evento político, não estava deslocada do imaginário social construído pelos jornalistas franceses em relação a uma manifestação política no Brasil.

Neste sentido, um primeiro ponto a ser destacado é a semelhança de perspectiva dos dois jornais. Le Monde e Libération são bastante 
diferentes em estilo, conteúdo e perfil de leitor. Estes dois órgãos da imprensa francesa estabelecem inclusive um interessante contraponto entre si, sendo algumas vezes antagônicos e outras, complementares. Entretanto, eles lançam mãos de imagens e símbolos idênticos para falar do Brasil e de seus movimentos políticos.

A campanha das "Diretas Já" é o assunto de primeira página no Monde nos dias 18, 25, 26 e 27 de abril. No dia 18, aparece em um texto, semelhante a um editorial, embora não receba este título. Os outros três dias são reportagens assinadas pelo correspondente e têm os seguintes títulos: "Batalha no Brasil pela extensão da democracia", "Para eleição do presidente pelo voto direto Brasília realiza sua primeira manifestação" e "Vitória dos militares no Parlamento brasileiro". Vale lembrar que, como o jornal circula à tarde, ele tem impresso em seu cabeçalho a data do dia seguinte. Esta última reportagem enfatiza a tristeza e a decepção com o resultado da votação e descreve o clima após a decisão, assim como os rumores que circulavam durante o seu desenrolar.

Com Libération não é diferente. O Brasil e seu momento político vão ganhando cada vez mais espaço ao longo do mês de abril. Foram matéria de primeira página nos dias $12,18,25$ e 27 de abril, com os respectivos títulos: "Rio: um milhão de manifestantes pela democracia", "Brasil: samba do sufrágio universal", "Brasil: a maré democrata aos pé do Parlamento" e "A eleição do Presidente pelo voto direto foi rejeitada - Brasil: os generais cortam a música". Esta última reportagem, que ocupa duas páginas inteiras com fotos, descreve também o clima de expectativa e espera do milagre. Comenta a frustração, destaca a censura aos meios de comunicação e a novidade de a população de Brasília pela primeira vez se manifestar apesar das medidas de urgência.

Os dois jornais franceses parecem comungar de uma visão "entusiasmada" em relação ao movimento por entendê-lo como um avanço, como se o povo brasileiro tivesse conseguido sair do "estágio inicial", na perspectiva francesa, de relações pessoais e estivesse pronto para entrar em uma nova etapa, ao mesmo tempo em que a festa, a alegria e a música não tivessem que ser banidas. Ao ler estas matérias, me parece que em nenhum instante a questão da imparcialidade e da objetividade esteve presente enquanto preocupação primeira. Naturalmente, não quero dizer com isso que Le Monde e Libération não levam em conta estas regras jornalísticas, mas sem dúvida, elas têm outra dimensão. Le Monde não se limitou a dar os fatos, mas tentou mostrar ao seu leitor todo o processo político em curso no país, sem deixar de expressar sua crítica ao governo militar. As medidas de 
emergência estabelecidas em Brasília às vésperas da votação são um bom exemplo. Ambos jornais ressaltaram o objetivo do governo militar de evitar, de forma autoritáriá, que o povo demonstrasse seu desejo junto aos parlamentares.

Creio que as descrições, por exemplo, que um jornal francês faz da cena política brasileira - em particular do movimento e das manifestações pelas "Diretas Já" - são expressão de determinadas concepções de política correntes naquela sociedade. Ou seja, não é à toa que o lítulo de um dos editoriais do Libération de apoio à campanha foi "Le degré zero de la democracie" O grau zero da democracia, o ponto de partida de qualquer sociedade para conquistar a democracia na visão francesá é a realização de eleições livres e diretas para presidente. É como se fosse impossível para estes jornalistas pensar em um país - a França - por exemplo, sem a sua República, sua liberdade, igualdade, fraternidade.

Esta perspectiva presente nos jornais franceses se aproxima da idéia de etnocentrismo de T. Todorov (1993:21 e 22). Para Todorov o etnocentrismo "consiste em, de maneira indevida, erigir em valores universais os valores próprios à sociedade a que pertenço." Isso implica em que o etnocêntrico parta do particular e decida generalizá-lo por ser este familiar e presente em sua cultura. E o pensador afirma que os exemplos de etnocentrismo estiveram presentes na história do pensamento na França e em muitos outros países. No entunto, esse espírito denominado "clássico" foi identificado com o "espírito francês".

Neste sentido a idéia de democracia se tornou um valor universal para todas as sociedades e como tal uma meta a ser atingida. E dentro do ideal de democracia a realização de eleições livres é um marco fundamental. Rivière (1988:57) considera que, dentro da ideologia oficial das democracias, as eleições são uma das formas mais importantes de ritos políticos, fazendo crer que elas significam a manutenção do sistema. As eleições com seu princípio de livre escolha vêm reafirmar a possibilidade sempre presente de mudanças no quadro de forças.

\section{O exótico}

A maneira específica como um jornal vê, descreve e classifica os acontecimentos políticos é um importante ponto de partida. São inúmeras as reportagens que associam o movimento brasileiro à festa è à música, mostrando ambas como características brasileiras. Ainda que uma manifestação política seja compreensível para um leitor francês, é preciso ir buscar a sua especificidade, ou melhor. a sua excentricidade, uma vez que a manifestação política em si nos aproxima dos "civi- 
lizados", dos povos com uma democracia já instalada e sólida. Mas é o lado exótico o maior atrativo para o público.

Um bom exemplo desta referência ao exótico presente nas matérias é um trecho da grande reportagem publicada pelo Monde em 25 de abril de 1984. Ela ocupa boa parte da primeira página do jornal e prossegue na página 6 , dentro da reportagem intitulada "Batalha no Brasil para a extensão da democracia". Há uma retranca: "Fête". Neste trecho, o correspondente descreve a "festa" que começou muito bem, a seu ver, com massas humanas cantando, dançando e desfilando nas ruas, entre elas jovens de biquínis com slogan das "Diretas Já" e grandes nomes da música popular participando e fazendo canções. Em seguida ele afirma:

"Au pays de la macumba, on a exorcisé celui qui ne veut pas du suffrage universel comme on expulse, par la transe, le Malin. On a promené dans les défiles un dragon de carton pâte - le monstre des "indirectes"”.

"No país da macumba exorcizou-se aquele que não quer as eleiçôes diretas como expulsa-se pelo transe o Demônio. Circulou nos desfiles um dragão de papelão - o monstro das indiretas."

A leitura que é feita da campanha e do processo político em curso 92 naquele momento é a via da festa e da macumba. Não quero aqui negar o quanto a campanha pelas "Diretas Já" teve como um dos fatores do seu sucesso e unanimidade a associação da política com carnaval, da cidadania com brincadeira, das eleições com a música. Mas há uma busca do exótico nesta descrição do movimento, como se não fosse possível lutar com as forças da razão, como se fosse preciso lançar mão da religiosidade e do ocultismo para obtenção de uma vitória política. Octavio Souza (1994:127) discorre sobre o significado do termo exótico e do quanto o Brasil está a ele associado.

"O espectro semântico da palavra 'exótico' abrange descde o sentido denotativo de estrangeiro ou não nativo, até o sentido conotativo oriundo de sentimentos estéticos, sentido que expressa o charme ou a fascinação do que não é familiar, o estranhamento belo ou excitante."

Certamente o Brasil, aos olhos de um francês, é um país exótico. Mas em que medida estas reportagens favoráveis ao retorno da democracia no país vêm apenas reforçar uma imagem de exotismo. Da Matta (1986:18), também bastante preocupado em definir e discutir a identidade nacional, afirma que o Brasil está longe de ser o que gostaríamos que fosse. Até porque os nossos parâmetrọ são os modelos ocidentais, das democracias norte-americana e européias. 
"Essa classificação permite construir uma identidade social moderna de acordo com os critérios estabelecidos pelo Ocidente europeu a partir da Revolução Francesa e da Revolução Industrial. Aqui. somos definidos por meio de critérios "objctivos", quantitativos e claros. É assim. sabemos e descobrimos com surpresa, que algumas sociedades, se definem. Realmente, a Inglaterra. a França. a Alemanha c, sobretudo. os Estados Unidos são quase exclusivamente definidos por meio deste cixo classificatório que é. ele mesmo, invenção sua."

Se Le Monde enfatiza seu olhar para o Brasil através do texto. Libération explicita isso em uma das folos que ilustra a grande reportagem de duas páginas e chamada na primeira. publicada no jornal no dia 18 de abril. É a foto de uma jovem de costas, de biquíni e camiscta com slogan das "Diretas Já". E inevitável a associação com a imagem de um país tropical, de calor, praia e de corpos seminus. Na reportagem, há a descrição do comício de São Paulo que contou com a participação de inúmeros políticos de oposição, artistas e músicos acompanhados por uma multidão de dois milhões de pessoras. A abertura da matéria afirma que sempre se disse ser o povo brasileiro pouco politizado. mas ele se mobilizou com essa campanha que tem uma palavra de ordem simples e os princípios democráticos de 1789. Aqui fical evidente o pertencimento do jornal à França republicana e país de origem da Revolução Francesa, marco na construção das democracias ocidentais.

O tom da reportagem, cheia de gírias e jogos de palavras. buscal expressar a festa, ao mesmo tempo $\mathrm{cm}$ que o editorial assinado por Carlos de Sá Rego enfatiza o espírito político do movimento que está desatrclado de candidatos ou partidos.

"Au Brésil, ces mots d'ordre sont devenus chansons et les slogans. cris des supporters de football. Le jaune, couleur du drapeux brésilien, est devenu la couleur de toutes les manifs, mais aussi des maillots des footballeurs et des baigneuses, des pubs et des t-shirts. Face à cette vague jaune. les géneraux ne savent trop que faire."

"No Brasil, estas palanras de ordem tomaram-se cançós, slogans. e gritos de torcedores de futebol. O amarelo. cor da bandeira brasileira. tornou-se a cor de todas as manifestações e também dos calções dos jogadores de futebol. dos banhistas, dos anúncios, das camisetas. Diante desta onda amarcla os generais não sabem o que fiazer."

Um outro símbolo da identidade nacional - o lutebol - é utilizado na matéria. Aliás, o próprio Libération. em uma outra reportagem sobre a campanha pelas "Diretas Já". compara a espera do resultado da vola- 
ção da emenda Dante de Oliveira no Congresso Nacional com a expectativa de uma final de Copa do Mundo. E ressalta vários aspectos. Em primeiro lugar, a idéia de unanimidade. Como em um jogo do Brasil, estão todos torcendo pelo mesmo time - no caso, pela aprovação da emenda. Em segundo lugar: clima de euforia e expectativa que, aos olhos do jornalista francês, pode parecer estranho. O clima de torcida em torno da votação de uma emenda à lei só pode ser comparado a um jogo de futebol. E ainda a visão de que a política no Brasil é sentida e vivenciada dentro de uma outra lógica. Assim, "Brésil: la democratie comme une finale de foot" é a manchete da matéria do Libération de 26 de abril. Em seguida, o texto, ilustrado por uma foto de multidão com bandeiras e cartazes, descreve o momento.

"Feux d'artifice, cortèges, danses dans la rue...Les Brésiliens passaient hier une nuit digne d'une finale de coupe du monde pour attendre les résultats du vote du Congrés sur l'élection au suffrage direct du président de la République."

"Fogos de artifício, passeatas, danças na rua. Os brasileiros tiveram ontem uma noite digna de final de Copa do mundo para esperar os resultados da votação no Congresso das eleições diretas para presidente da República."

Ao longo da reportagem, está presente a noção expressa no próprio subtítulo "La politique comme plaisir". Ou seja, esta perspectiva de associar política e prazer parece algo estranho, senão novo, para os franceses. A presença da Mangueira, de grandes cantores populares, de artistas de teatro e de televisão reforça a idéia explicitada por um entrevistado na matéria. Ele afirma que algo mudou no país; as pessoas descobriram que a política deve ser um prazer.

Creio também que a presença de artistas e políticos nos comícios aponta o caráter personalista da nossa sociedade. Muito já se discutiu sobre os elementos que atuam em uma escolha eleitoral. Voto de "cabresto", compromissos pessoais, relações familiares, troca de favores são sem dúvida elementos de influência nesta escolha. Isto porque a noção de cidadania como é entendida nas sociedades do "Primeiro Mundo" diz respeito ao conceito de indivíduo, de regras universais, tudo isto ligado a uma racionalidade, como salientou Da Matta (1987). No Brasil a relação de pessoalidade tem uma dimensão que certamente influi na construção da cidadania. Sérgio Buarque de Holanda (1984:31) já afirmava isso ao analisar o Brasil colônia.

"O peculiar da vida brasileira parece ter sido, por essa época uma 
acentuação singularmente enérgica do afetivo, do irracional. do passional, e uma estagnação ou antes uma atrofia correspondente das qualidades ordenadoras, disciplinadoras. racionalizadoras. Quer dizer, exatamente o contrário do que parece convir a uma população em vias de organizar-se politicamente."

O Brasil ocupa um lugar intermediário entre um tipo de socicdade ocidental, individualista, igualitária e moderna e o tipo oposto, como a sociedade indiana por exemplo, hierárquica, holista c tradicional. Convivem e dialogam em seu interior ideologias individualistas e igualitárias com outras holistas e tradicionais, sem hegemonia de nenhuma delas. É Da Matta(1985:21) também quem afirma que "O universalismo é demandado em priblico pelo Estado moderno, individualista e impessoal, mas o particularismo continua a imperar no plano pessoal e doméstico." E para a imprensa estrangeira todo esse equilíbrio não é simples de entender. Como declarava o macstro Tom Jobim : "O Brasil não é para principiantes".

Não resta dúvida que. para um jornalista francês. muitas vozes acostumado à tradicional e sisuda política nacional. pareça estranho e exótico transformar un comício pelas "Diretas" em festa. Os dois jornais franceses procuraram ao longo de (oda sua cobertura dar conta do significado daquele evento político para o país e para a próprial França, a mesmo tempo em que buscaram transmitir ao leitor o "tom" c o "clima" presentes. Manchetes como "Brésil: an carnaral déjà électoral" não demonstram uma intencionalidade de estercotipar o país, mas apresentar um elemento de reconhecimento para o leitor. De que país se fala? Do país do carnaval. E o carnaval é um elemento de identificação do Brasil no exterior.

Mas se por um lado os jornalistas franceses estão apontando e salientando as diferenças e singularidades brasileiras em suas reportagens e manchetes, esta não parece ser uma prática exclusiva do jornalismo francês. Se o Brasil está muitas vezes associado a uma série de clichês nas cabeças estrangeiras, sendo pintado e descrito com mulatas sambando, praias repletas, muita música, futebol e cultos religiosos; elementos presentes na nossa cultura. os quais não podemos negar a existência. o que está em jogo é a capacidade de redução. De transformar um país tão grande e complexo, cm símbolos e imagens restritas. Por outro lado, se pensarmos. ainda que intuitivamente. na cobertura que a imprensa brasileira faz da França. veremos que a imagem da Torre Eiffel e dos scus inúmeros tipos de queijo e vinho são os chavões mais freqüentes.

Os jornalistas ao redigirem suas matérias estão impregnados de 
uma visão de mundo extremamente influenciada pela profissão e pela capacidade de definir o que é notícia. Por outro lado, precisam ser capazes de transmitir o máximo de informação no menor espaço e tempo possíveis, com fácil compreensão do leitor. Neste sentido, a linguagem jornalística e sua técnica colaboram muitas vezes com esses reducionismos e estereótipos.

Pierre Bourdieu (1997:25) ao criticar a imprensa e os jornalistas, afirma que os jornalistas têm "óculos" especiais a partir dos quais vêem o mundo. E com estes "óculos" operam uma seleção e uma construção a partir do que é selecionado. Para isto é fundamental a busca do sensacional e do espetacular, e principalmente apresentar o objeto com as categorias de percepção do receptor. Ainda que eu discorde de parte da crítica de Bourdieu, creio ser esse um ponto fundamental pạra avaliação da cobertura das "Diretas Já" pela imprensa francesa. A perspectiva do leitor parece estar presente o tempo todo, como se o jornal precisasse dar ao seu público a possibilidade de reconhecer aquele assunto. De identificá-lo. E para tal lançasse mão dos clichês. Brasil da música, do carnaval e do futebol mesmo na política.

\section{Conclusão}

Ao longo deste ensaio busquei investigar qual o olhar dos jornalistas e da imprensa francesa para o Brasil a partir da cobertura jornalística da campanha pelas eleições diretas no mês de abril de 1984. Não procurei fazer aqui uma dissecação minuciosa de textos, fotos e títulos, mas, a partir de um levantamento inicial sobre o lugar dos dois jornais escolhidos - Le Monde e Libération - no campo jornalístico francês e internacional, perceber quais os elementos fundamentais para a descrição e compreensão do processo político que estava em curso no Brasil naquele momento.

Foi inevitável notar o quanto os jornais apresentavam mais semelhanças do que poderia supor inicialmente e, à parte as especificidades de estilo e forma de cada um deles, ambos deram tratamento bastante parecido ao evento. Partiram do pressuposto que eleições diretas para presidente são uma reivindicação elementar de qualquer democracia ocidental e, em função disso, parecia óbvio aos dois jornais apoiar este movimento.

Um dos fatos surpreendentes percebidos na análise do material foi a quantidade de notas, reportagens e matérias sobre o Brasil no mês de abril de 1984. Outra surpresa foi a dimensão que a campanha pelas "Diretas Já" ganhou ao longo do mês nos dois jornais. As matérias cresceram na mesma proporção que o movimento. Se Le Monde foi 
mais sisudo que o Libération, em nenhum momento os dois cotidianos deixaram de expressar suas posições de apoio ao movimento.

Ficou claro ao longo da leitura dos textos que havia uma preocupação com o leitor francês e a sua compreensão da realidade brasileira. De certa maneira este público orientou a perspectival dos jornais. As reportagens não acrescentaram informações substanciais sobre o país ou a sua conjuntura política e econômica. Não romperam com imagens e símbolos previsíveis, ao contrário reforçaram os já estabelecidos. O Brasil continuou sendo a terra do samba, do carnaval, do fucbol.

\section{Notas}

1 Esta matéria está alocada na editoria de economia, diferentemente de todas as outras.

\section{Bibliografia}

BOURDIEU, Pierre. Sobre televisão. Rio de Janeiro. Zahar. 1997.

CHARLE, Christophe. Naissance des intellectuels. Paris, Minuit. 1990.

CONTI, Mário Sergio. Notícias do Planalto. SP, Companhia das Letras, 1999.

DA MATTA. Roberto. Carnavais, malandros e heróis. Rio de Janeiro. Zahar, 1981.

A casa $\&$ a rua; espaço, cidadania, mulher e morte no Brasil. Rio de Janeiro, Guanabara, 1987.

Guanabara, 1986.

O que faz o Brasil, brasil. Rio de Janeiro.

DARNTON, R. O beijo de Lamourette. SP. Companhia das Letras. 1990.

DINES. Alberto. O papel do jornal. São Paulo, Summus Editorial. 1986.

DURKHEIM, E. \& MAUSS, M. "Algumas formas primitiras de classificação. Contribuição para o estudo das representações coletivas." In: MAUSS, M. Ensaios de Sociologia. São Paulo. Perspectiva. 1981. 
GOMES, Laura G: BARBOSA, Lívia \& DRUMOND, J. A.(orgs) O Brasil não é para principiantes: carnavais, malandros e heróis, 20 anos depois. RJ, FGV, 2000.

HOLANDA, Sérgio Buarque. Raízes do Brasil. Rio de Janeiro, José Olympio, 1984.

JEANNENEY, Jean Noël. Une histoire des médias. Paris, Seuil, 1996.

LATTMAN-WELTMAN, F. \& CARNEIRO, J. A.D.A. A imprensa faz e desfaz um presidente. Rio de Janeiro, Nova Fronteira, 1994.

LÉVI-STRAUSS, Claude. O olhar distanciado. Lisboa, Edições 70, 1982.

MOLLIER, Jean Yves. "La presse et l'édition dans bataille dreyfusienne". In: Revue du Musée d'Orsay. Paris, 48/ 14(1):76-85, 1995 .

ROCHA, Everardo G. O que é etnocentrismo. SP, Brasiliense, 1984.

RIVIÉRE, Claude. Les liturgies politiques. Paris, Presses Universitaires de France, 1988

98 SOUZA, Octavio. Fantasia de Brasil. São Paulo, Escuta, 1994.

TODOROV, Tzvetan. Nós e os outros- a reflexão francesa sobre a diversidade humana -I. RJ, Jorge Zahar. 1993.

TRAVANCAS, Isabel . O mundo dos jornalistas. São Paulo, Summus Editorial, 1993.

VELHO, Gilberto. Individualismo e cultura. Rio de Janeiro, Zahar. 1987.

Palavras-chave:

1. imprensa;

2. jornalismo;

3. exótico;

4. cobertura internacional;

5. eleições diretas 